Check for updates

Cite this: RSC Adv., 2018, 8, 26793

\title{
Viscoelastic and self-healing behavior of silica filled ionically modified poly(isobutylene-co-isoprene) rubber $\dagger$
}

\author{
Aladdin Sallat, (D) ${ }^{\text {ab }}$ Amit Das, (D) ${ }^{a}$ Jana Schaber, ${ }^{a}$ Ulrich Scheler, ${ }^{a}$ \\ Eshwaran S. Bhagavatheswaran, ${ }^{a}$ Klaus W. Stöckelhuber, (D) a Gert Heinrich, ${ }^{\text {ac }}$ \\ Brigitte Voit (D) ab and Frank Böhme (D) *a
}

\begin{abstract}
Rubber composites were prepared by mixing bromobutyl rubber (BIIR) with silica particles in the presence of 1-butylimidazole. In addition to pristine (precipitated) silica, silanized particles with aliphatic or imidazolium functional groups, respectively, were used as filler. The silanization was carried out either separately or in situ during compounding. The silanized particles were characterized by TGA, ${ }^{1} \mathrm{H}-{ }^{29} \mathrm{Si}$ cross polarization (CP)/MAS NMR, and Zeta potential measurements. During compounding, the bromine groups of BIIR were converted with 1-butylimidazole to ionic imidazolium groups which formed a dynamic network by ionic association. Based on DMA temperature and strain sweep measurements as well as cyclic tensile tests and stress-strain measurements it could be concluded that interactions between the ionic groups and interactions with the functional groups of the silica particles strongly influence the mechanical and viscoelastic behavior of the composites. A particularly pronounced reinforcing effect was observed for the composite with pristine silica, which was attributed to acid-base interactions between the silanol and imidazolium groups. In composites with alkyl or imidazolium functionalized silica particles, the interactions between the filler and the rubber matrix form dynamic networks with pronounced self-healing behavior and excellent tensile strength values of up to $19 \mathrm{MPa}$. This new approach in utilizing filler-matrix interactions in the formation of dynamic networks opens up new avenues in designing new kinds of particle-reinforced self-healing elastomeric materials with high technological relevance.
\end{abstract}

Received 30th May 2018

Accepted 19th July 2018

DOI: $10.1039 / c 8 r a 04631 j$

rsc.li/rsc-advances

\section{Introduction}

After the first description of a self-healing rubber by Leibler et al., ${ }^{1}$ a series of publications appeared which aimed to implement self-healing behavior in commercial rubbers. This included materials like natural rubber, ${ }^{2-4}$ chloroprene rubber, ${ }^{5}$ polybutadiene, ${ }^{6}$ acrylonitrile butadiene rubber, ${ }^{7}$ styrene butadiene rubber, ${ }^{8}$ and polydimethylsiloxane. ${ }^{9,10}$ In order to facilitate self-healing, both physical ${ }^{6-9}$ and reversible covalent crosslinking $^{2-5}$ have been utilized in these rubber systems, with strong focus on the basic principles of self-healing. In recent publications, the self-healing behavior of rubber composites

${ }^{a}$ Leibniz Institut für Polymerforschung Dresden, Hohe Straße 6, D-01062 Dresden, Germany.E-mail:boehme@ipfdd.de

${ }^{b}$ Organische Chemie der Polymere, Technische Universität Dresden, D-01062 Dresden, Germany

'Institut für Textilmaschinen und Textile Hochleistungswerkstofftechnik, Technische Universität Dresden, D-01069 Dresden, Germany

$\dagger$ Electronic supplementary information (ESI) available: TEM micrographs (SI1), sample transparency (SI2), DMA curves (SI3 and SI4), mechanical hysteresis curves (SI5), and stress-strain curves (SI6 and SI7) of composites $\mathbf{C}_{3-5}$ in comparison to $\mathbf{C}_{\mathbf{0}-2}$ and BIIR-i. See DOI: $10.1039 / \mathrm{c} 8 \mathrm{ra} 04631 \mathrm{j}$ has met increasing interest in materials research. Here, emphasis is put on carbon mixtures, the electrical conductivity of which is used for sensoric and electronic applications ${ }^{11-13}$ or Joule heating induced self-healing. ${ }^{14}$ In another example, IR laser induced self-healing was described for a graphene containing polyurethane rubber applicable in flexible electronics. ${ }^{15}$ A further example is a mixture with metallic fibers in which selfhealing was pursued by microwave heating..$^{16}$ However, the influence of reinforcing fillers on the self-healing behavior of rubber composites has received little attention so far.

Generally, compounding of technical rubbers with special fillers is a necessary measure to adapt material properties for respective technical applications, e.g. in tire components. This also applies to self-healing rubbers. The extent to which the additional interactions of the polymer matrix with the filler influence material properties of self-healing rubbers has not been sufficiently investigated yet.

In this publication, we describe silica-rubber composites, the properties of which were adjusted via matrix-filler interactions. Ionically modified bromobutyl rubber (BIIR-i), which served as the rubber matrix, was prepared by conversion of BIIR with 1butylimidazole (1) (see Scheme 1). This kind of modification 


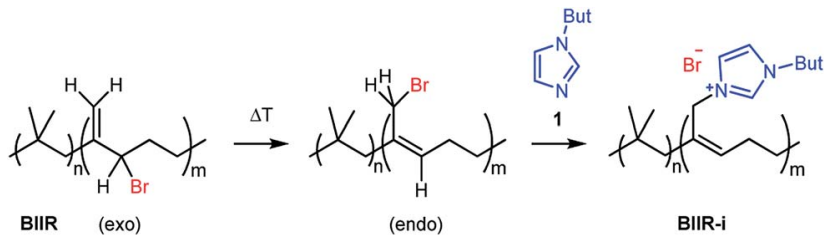

Scheme 1 lonic modification of bromobutyl rubber by conversion with 1-butylimidazole.

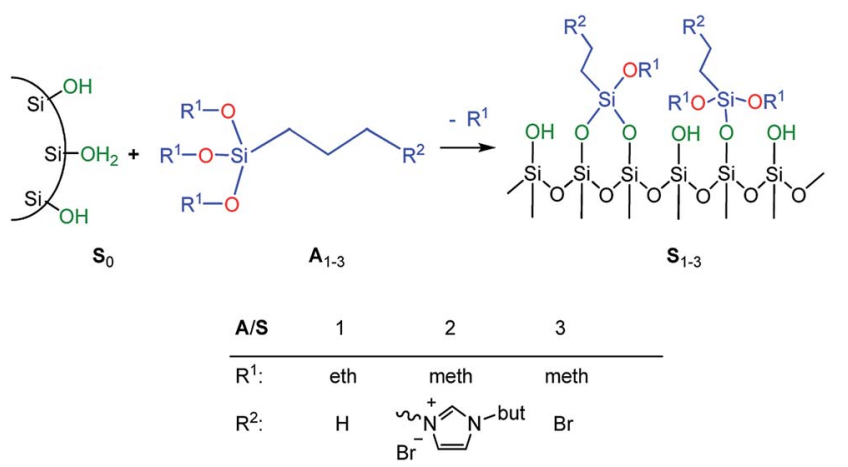

Scheme 2 Silanization of precipitated silica (Ultrasil 7000GR).

was first described by Parent et al. ${ }^{17,18}$ In our own work, we have recently demonstrated that such modified rubbers show a pronounced tendency to self-heal. ${ }^{19,20}$ This self-healing effect was attributed to the formation and rearrangement of ionic clusters. Introduction of carbon nanotubes into BIIR-i facilitated self-healing by Joule heating. ${ }^{21,22}$ The aim of the present work was to determine to which extent the properties of BIIR can be further improved by the addition of silica without sacrificing self-healing. Our investigations show the general possibility of implementing self-healing behavior in technically relevant rubber formulations through ionic interactions. This approach is not limited to BIIR but might also be useful for other technical rubbers. Due to the self-healing behavior, it is expected that micro cracks formed during use will be repaired immediately, resulting in longer lifespans and preventing total material failure. ${ }^{19}$

In order to adjust the interactions between the rubber matrix and the filler, the filler surface was modified by silanization with three alkoxysilanes as shown in Scheme 2. Here, two different approaches were followed. In the first approach, the silica particles were silanized separately (ex situ) and then mixed with the rubber. In the second approach, the silanization was performed during mixing (in situ). The influence of different alkoxysilanes and mixing procedures on the material properties is discussed.

\section{Experimental}

\section{Materials}

1-Butylimidazole (1) (Sigma-Aldrich, 98\%), n-propyltriethoxysilane ( $\left.\mathbf{A}_{\mathbf{1}}\right)$ (abcr, 97\%), (3-bromopropyl)trimethoxysilane $\left(\mathbf{A}_{\mathbf{3}}\right)$ (abcr, 97\%), toluene (Aldrich, anhydrous 99.8\%), and methanol
(Acros Organics, 99.9\%) were used as received. Precipitated silica Ultrasil@ $7000 \mathrm{GR}\left(\mathbf{S}_{\mathbf{0}}\right)$ with a specific surface area (BET) of $175 \mathrm{~m}^{2} \mathrm{~g}^{-1}$ and a primary particle size of $10 \mathrm{~nm}$ was supplied by Evonik Industries. Bromobutyl rubber (BIIR) is a commercial product of Lanxess with a bromine content of $1.13 \mathrm{wt} \%$ ( $0.80 \mathrm{~mol} \%$ brominated isoprene units) determined by ${ }^{1} \mathrm{H}$ NMR. Ionically modified bromobutyl rubber (BIIR-i) was obtained by conversion of BIIR with $\mathbf{1}$ (see Scheme 1) as described earlier. $^{19,20}$

\section{1-Butyl-3-(trimethoxysilylpropyl)imidazolium bromide $\left(\mathbf{A}_{\mathbf{2}}\right)$}

A mixture of (3-bromopropyl)trimethoxysilane (35 mL, 267 $\mathrm{mmol}$ ) and 1-butylimidazole $(50 \mathrm{~mL}, 267 \mathrm{mmol})$ was stirred in a dried round bottom flask for 5 days at room temperature. $\mathbf{A}_{2}$ was obtained as yellow viscous oil which was used without further purification.

${ }^{1} \mathrm{H}$ NMR $\left(\mathrm{CDCl}_{3} \mathrm{ppm}\right): \delta_{\mathrm{H}}=10.57\left(1 \mathrm{H}, \mathrm{s}, \mathrm{Im}-\mathrm{H}^{9}\right) 7.46(1 \mathrm{H}, \mathrm{s}$, Im- $\mathrm{H}^{10}$ alt 11$) 7.39\left(1 \mathrm{H}, \mathrm{s}, \mathrm{Im}-\mathrm{H}^{10}\right.$ alt 11$), 4.36\left(4 \mathrm{H}, \mathrm{m}, \mathrm{H}^{4,5}\right), 3.55$ $\left(9 \mathrm{H}, \mathrm{s}, \mathrm{H}^{1}\right), 2.01\left(2 \mathrm{H}, \mathrm{t}, \mathrm{H}^{3}\right.$ alt 6$), 1.91\left(2 \mathrm{H}, \mathrm{t}, \mathrm{H}^{3}\right.$ alt 6$), 1.38(2 \mathrm{H}, \mathrm{m}$, $\left.\mathrm{H}^{7}\right), 0.95\left(3 \mathrm{H}, \mathrm{t}, \mathrm{H}^{8}\right), 0.63\left(2 \mathrm{H}, \mathrm{t}, \mathrm{H}^{2}\right)$.

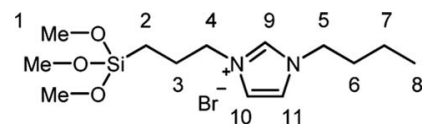

\section{Silanization of silica particles $\left(\mathrm{S}_{1-3}\right)$}

Three different types of surface-modified silica particles were obtained by silanization of $\mathbf{S}_{\mathbf{0}}$ with alkoxysilanes such as $n$ propyltriethoxysilane $\quad\left(\mathbf{A}_{\mathbf{1}}\right)$, 1-butyl-3-(trimethoxysilylpropyl) imidazolium bromide $\left(\mathbf{A}_{\mathbf{2}}\right)$, and (3-bromopropyl)trimethoxysilane $\left(\mathbf{A}_{\mathbf{3}}\right)$ respectively. The silanization was performed as follows: an amount of $15 \mathrm{~g}$ Ultrasil $₫ 7000 \mathrm{GR}$ were suspended in $250 \mathrm{~mL}$ of dry toluene in a dried $500 \mathrm{~mL}$ round bottom flask equipped with a reflux condenser. An excess of the alkoxysilane ( $2.8 \mathrm{mmol} \mathrm{g}^{-1}$ silica) was added while stirring. The suspension was heated under reflux for $24 \mathrm{~h}$. Then, methanol formed during the reaction was distilled off. After cooling, the modified silica particles were collected by centrifugation and thoroughly washed with methanol. The product was then dried at $110^{\circ} \mathrm{C}$ for $12 \mathrm{~h}$.

\section{Preparation of silica-rubber composites $\left(\mathrm{C}_{0-5}\right)$}

An amount of $50 \mathrm{~g}$ BIIR (6.94 mmol allylic bromide) and $1.41 \mathrm{~g}$ of 1-butylimidazole $(11 \mathrm{mmol})$ were premixed in an internal mixer (Haake Rheomix, Thermo Electron GmbH, Karlsruhe, Germany) for $10 \mathrm{~min}$ with a rotor speed of $60 \mathrm{rpm}$ at $40{ }^{\circ} \mathrm{C}$. Under these conditions, grafting reactions according to Scheme 1 can be neglected. This mixture was used as a master batch for the preparation of composites $\mathbf{C}_{\mathbf{0 - 5}}$. Two different methods were used for the preparation of the composites.

Ex situ silanization approach $\left(\mathbf{C}_{1-3}\right)$. A portion of the BIIR/1butylimidazole master batch was mixed with $30 \mathrm{phr}$ of the presilanized silica particles $\mathbf{S}_{\mathbf{1 - 3}}$ in an internal mixer with a rotor speed of $50 \mathrm{rpm}$ at $40^{\circ} \mathrm{C}$ for $10 \mathrm{~min}$. After that, the compounded mass was homogenized in a laboratory size two-roll mixing mill 
(Polymix 110L, size $203 \times 102 \mathrm{~mm}$, Servitech $\mathrm{GmbH}$, Wustermark, Germany) at $50{ }^{\circ} \mathrm{C}$ for 2 min and then molded under pressure at $120^{\circ} \mathrm{C}$ for $30 \mathrm{~min}$. Using the same method, a reference sample $\left(\mathbf{C}_{\mathbf{0}}\right)$ was prepared by mixing the master batch with pristine silica $\mathbf{S}_{\mathbf{0}}$.

In situ silanization approach $\left(\mathbf{C}_{4-5}\right)$. A portion of the BIIR/1butylimidazole master batch was mixed with $30 \mathrm{phr}$ of pristine silica $\mathbf{S}_{\mathbf{0}}$ in an internal mixer with a rotor speed of $50 \mathrm{rpm}$ at $110{ }^{\circ} \mathrm{C}$ for $2 \mathrm{~min}$. Then, an amount of $2.5 \mathrm{phr}$ of the silane coupling agent $\left(\mathbf{A}_{\mathbf{1}}, \mathbf{A}_{\mathbf{3}}\right)$ was added and allowed to react with the silica for $5 \mathrm{~min}$. During that time, the temperature raised rapidly to $140{ }^{\circ} \mathrm{C}$. After that, the compounded mass was homogenized in a laboratory size two-roll mixing mill at $50{ }^{\circ} \mathrm{C}$ for two min and then molded under pressure at $120{ }^{\circ} \mathrm{C}$ for $30 \mathrm{~min}$. The amount of added silane coupling agent was calculated as described by Mihara et al. ${ }^{23}$

In both cases, the formation of BIIR-i according to Scheme 1 occurred in situ during processing at temperatures higher than $100{ }^{\circ} \mathrm{C}$. A sample overview is given in Table 1 . After molding, test bars of the composites were punched out of the sheet obtained and used for mechanical and self-healing tests. The transparency of all samples indicates a homogeneous particle distribution. This is confirmed by TEM images of selected samples (see ESI SI1 and SI $2 \dagger$ ).

\section{Characterization}

${ }^{1} \mathrm{H}$ NMR (500.13 MHz) spectra were recorded on an Avance III $500 \mathrm{NMR}$ spectrometer (Bruker). $\mathrm{CDCl}_{3}\left(\delta\left({ }^{1} \mathrm{H}\right)=7.26 \mathrm{ppm}\right)$ was used as the solvent and internal standard.

${ }^{1} \mathrm{H}^{-29} \mathrm{Si}$ cross polarization (CP)/MAS NMR spectra were recorded using an Avance III $300 \mathrm{MHz}$ spectrometer (Bruker, Karlsruhe, Germany) with a double resonance HX $4 \mathrm{~mm}$ MAS probe head as described by Fischer et al. ${ }^{24} \mathrm{Q} 8 \mathrm{M} 8\left(\delta\left(\mathrm{Si}\left(-\mathrm{CH}_{3}\right)_{3}\right)=\right.$ $12.6 \mathrm{ppm}$ ) was used as reference for ${ }^{29} \mathrm{Si}$. The CP/MAS NMR experiments were carried out with a $\pi / 2$ pulse duration of $4 \mu \mathrm{s}$ for ${ }^{1} \mathrm{H}$, a contact time $\tau$ of $2 \mathrm{~ms}$ and 20000 scans at a MAS spinning rate of $10 \mathrm{kHz}$. One pulse $1 \mathrm{H}$ MAS NMR experiments were also carried out using a $\pi / 2$ pulse duration of $4 \mu$ s and 10 scans at a MAS spinning rate of $10 \mathrm{kHz}$.

Thermogravimetric analysis was performed using a TGA Q 5000 (TA instruments, New Castle, DE, USA) with a heating rate of $10 \mathrm{~K} \mathrm{~min}^{-1}$ under nitrogen atmosphere. The weight loss from 50 to $800{ }^{\circ} \mathrm{C}$ was measured.

Zeta potential measurements were performed on pristine $\left(\mathbf{S}_{\mathbf{0}}\right)$ and modified silica particles $\left(\mathbf{S}_{\mathbf{1 - 3}}\right)$ using a Zetasizer Nano (Malvern Instruments Inc., Malvern, UK). The determination of the Zeta potential was based on the electrophoretic mobility measured at a voltage of $40 \mathrm{~V}$ and an electrode distance of $5 \mathrm{~cm}$. The samples (each $30 \mathrm{mg}$ ) were dispersed in $30 \mathrm{~mL}$ of an aqueous solution of $\mathrm{KCl}\left(c=10^{-3} \mathrm{~mol} \mathrm{~L}^{-1}\right)$ in an ultrasonic bath. The $\mathrm{pH}$ was adjusted with $\mathrm{HCl}$ and $\mathrm{KOH}\left(c=0.1 \mathrm{~mol} \mathrm{~L}^{-1}\right)$. With the measured electrophoretic mobility

$$
\mu=\nu / E,
$$

the Zeta potential $\zeta$ was calculated using the simple Smoluchowski equation:

$$
\zeta=\frac{v}{E} \frac{\eta}{\varepsilon \varepsilon_{0}}
$$

where $\nu$ is the drift velocity, $\eta$ is the viscosity, $E$ is the electric field strength, $\varepsilon$ is the dielectric constant, and $\varepsilon_{0}$ is the vacuum permittivity.

Dynamic mechanical analysis (DMA) was performed on standard test bars $(5 \times 10 \times 2 \mathrm{~mm})$ with a thermal spectrometer (EPLEXOR 2000N) from GABO QUALIMETER, Ahlden, Germany. The temperature sweep measurements were carried out in tensile mode and in a temperature range from -80 to $+80{ }^{\circ} \mathrm{C}$ with a heating rate of $2 \mathrm{~K} \mathrm{~min}^{-1}$ at a frequency of $10 \mathrm{~Hz}$ under $0.5 \%$ (dynamic) and $1 \%$ (static) strain. The strain sweep measurements were performed at a constant frequency of $10 \mathrm{~Hz}$ with $60 \%$ pre-strain and dynamic strain from $0.01-30 \%$.

Tensile tests were carried out on a Zwick 1456 universal testing machine at a constant stretch rate of $200 \mathrm{~mm} \mathrm{~min}^{-1}$ according to DIN EN ISO 527-2/S2/20.

\begin{tabular}{|c|c|c|c|c|c|}
\hline BIIR-i & 100 & 3 & - & - & - \\
\hline $\mathbf{C}_{\mathbf{1}}^{a, b}$ & 100 & 3 & $30\left(\mathbf{S}_{\mathbf{1}}\right)$ & - & \\
\hline $\mathbf{C}_{3}^{b, c}$ & 100 & 3 & $30\left(\mathbf{S}_{3}\right)$ & - & $\equiv$ \\
\hline $\mathbf{C}_{\mathbf{4}}{ }^{c, d}$ & 100 & 3 & $30\left(\mathbf{S}_{\mathbf{0}}\right)$ & $2.5\left(\mathbf{A}_{1}\right)$ & \\
\hline $\mathbf{C}_{5}^{c, d}$ & 100 & 3 & $30\left(\mathbf{S}_{\mathbf{0}}\right)$ & $2.5\left(\mathbf{A}_{3}\right)$ & \\
\hline
\end{tabular}

Table 1 Sample overview

${ }^{a}$ No change in surface functionality during compounding. ${ }^{b}$ Ex situ particle silanization approach. ${ }^{c}$ Change in surface functionality during compounding. ${ }^{d}$ In situ particle silanization approach. ${ }^{e}$ Functional groups on the particle surface after compounding. 
Self-healing tests were performed as described earlier. ${ }^{20}$ For this, test bars of the composites were placed in a custom-built test device, cut with a razor blade and then pressed together with a defined compression of $0.2 \mathrm{~mm}$. In this state, the samples were allowed to heal for $16 \mathrm{~h}$ at $70{ }^{\circ} \mathrm{C}$ and then stored at room temperature. Finally, the mended samples were subjected to tensile tests. The tensile stress $\left(\sigma_{\mathrm{b}}\right)$ - and elongation at break $\left(\varepsilon_{\mathrm{b}}\right)$-related healing efficiencies $H_{\sigma}$ and $H_{\varepsilon}$ (in \%) were calculated from the ratios of the respective parameters of the virgin and the healed samples.

\section{Results and discussion}

\section{Surface-modified silica particles}

The preparation of suitable composites based on silica and ionically modified rubber (BIIR-i) requires an adjustment of the interactions between the silica particles and the matrix. For this, the surface of silica (Ultrasil ${ }^{\circledR} 7000 \mathrm{GR}$ ) was silanized according to Scheme 2 using three different alkoxysilanes $\left(\mathbf{A}_{\mathbf{1}-3}\right)$. The modification with $\mathbf{A}_{\mathbf{1}}\left(\mathbf{S}_{\mathbf{1}}\right)$ aimed to adapt the interactions of the particles with the hydrophobic backbone of BIIR-i, whereas with $\mathbf{A}_{\mathbf{2}}\left(\mathbf{S}_{2}\right)$, an improvement of the interactions with the ionic part of BIIR-i was envisioned. Surface modification with $\mathbf{A}_{\mathbf{3}}$ provided silica particles with reactive bromine groups at the surface $\left(\mathbf{S}_{3}\right)$ to be used for the in situ formation of ionic groups on the silica surface during mixing with BIIR/1-butylimidazole.

Pristine silica $\mathbf{S}_{\mathbf{0}}$ and the pre-silanized (ex situ) silicas $\mathbf{S}_{\mathbf{1 - 3}}$ were characterized by TGA in the temperature range from 20 to $800{ }^{\circ} \mathrm{C}$. According to the thermograms shown in Fig. 1, all samples revealed an initial weight loss at temperatures up to $100{ }^{\circ} \mathrm{C}$. This is due to the removal of physically adsorbed water and any solvent residues remaining from the modification process. Up to $200{ }^{\circ} \mathrm{C}$ the physically adsorbed water is completely removed. In the region from 200 to $800{ }^{\circ} \mathrm{C}$, a gradual weight loss is observed for the unmodified silica $\mathbf{S}_{\mathbf{0}}$ (Fig. 1), which is attributed to dehydroxylation reactions, in which silanol groups condense to siloxane bridges. ${ }^{25}$

The alkyl modified silica $\mathbf{S}_{\mathbf{1}}$ exhibits gradual thermal degradation from 200 to $520{ }^{\circ} \mathrm{C}$ and a pronounced degradation step at $540{ }^{\circ} \mathrm{C}$. For the bromopropyl modified sample $\mathbf{S}_{3}$, a very broad

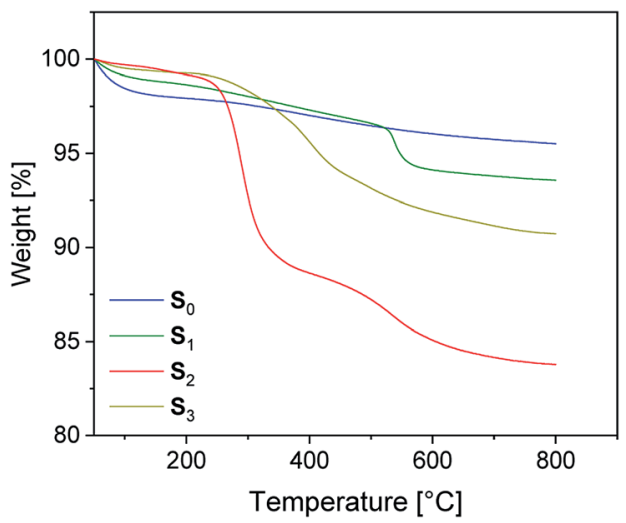

Fig. 1 TGA traces for unmodified silica $S_{0}$ and surface-modified silicas $\mathrm{S}_{1-3}$.
Table 2 Thermogravimetric weight loss of unmodified- $\left(\mathrm{S}_{0}\right)$ and modified silica $\left(\mathrm{S}_{1}-\mathrm{S}_{3}\right)$

\begin{tabular}{lllll}
\hline Temperature $\left[{ }^{\circ} \mathrm{C}\right]$ & $\mathbf{S}_{\mathbf{0}}[\%]$ & $\mathbf{S}_{\mathbf{1}}[\%]$ & $\mathbf{S}_{\mathbf{2}}[\%]$ & $\mathbf{S}_{\mathbf{3}}[\%]$ \\
\hline $200-400$ & 0.9 & 1.2 & 10.5 & 3.7 \\
$400-700$ & 1.3 & 3.5 & 4.5 & 4.5 \\
$200-700$ & 2.2 & 4.7 & 15.0 & 8.1
\end{tabular}

degradation step above $200{ }^{\circ} \mathrm{C}$ is found, whereas the ionically modified $\mathbf{S}_{2}$ exhibits two pronounced degradation steps at about 270 and $550{ }^{\circ} \mathrm{C}$. It is assumed that the degradation behavior of the modified samples $\mathbf{S}_{\mathbf{1 - 3}}$ is superimposed by three different degradation processes. The first one is the dehydroxylation of remaining silanol groups as already discussed for $\mathbf{S}_{\mathbf{0}}$. The others are the decomposition of the functional groups $(\mathrm{Br}$ and imidazolium, respectively) and of the surface-bonded residual alkoxy side groups. ${ }^{26}$ The TGA curve of $\mathbf{S}_{\mathbf{1}}$ suggests that the latter decompose at higher temperatures. The very broad degradation step of $\mathbf{S}_{3}$ above $200{ }^{\circ} \mathrm{C}$ is assumed to be the result of a superposition of debromination and decomposition of the alkoxy side groups.

The weight loss of the alkoxysilane modified silica particles above $200{ }^{\circ} \mathrm{C}$ is compared to that of unmodified silica. The results are listed in Table 2 . From the values of unmodified silica we can conclude that the dehydroxylation process on the surface accounts for a $2 \%$ weight loss. The modified silicas $\mathbf{S}_{\mathbf{1}}$ and $S_{3}$ have a total weight loss of 4.7 and $8.1 \%$ respectively, while the modified silica $S_{2}$ has a total weight loss of $15 \%$.

Final proof for the grafting of alkoxysilanes on the silica surface was obtained by ${ }^{29} \mathrm{Si} \mathrm{CP} / \mathrm{MAS}$ NMR spectroscopy as previously described. ${ }^{24}$ These investigations were carried out with $\mathbf{S}_{2}$ as an example. Fig. 2 shows the ${ }^{29} \mathrm{Si}$ CP/MAS NMR spectra of $\mathbf{S}_{\mathbf{0}}$ and $\mathbf{S}_{2}$. In the spectrum of $\mathbf{S}_{\mathbf{0}}$, the typical $\mathrm{Q}_{2}, \mathrm{Q}_{3}$, and $\mathrm{Q}_{4}$ signals belonging to geminal $\left(=\mathrm{Si}-(\mathrm{OH})_{2}\right)$ and vicinal silanol ( $\equiv \mathrm{Si}-\mathrm{OH})$ groups as well as to siloxane bridges $(\mathrm{Si}-(\mathrm{O}-$ $\mathrm{Si}_{4}$ ), respectively, are visible. ${ }^{27}$ After conversion with $\mathbf{A}_{2}$, two new signals appeared at $-57\left(\mathrm{~T}_{2}\right)$ and $-66 \mathrm{ppm}\left(\mathrm{T}_{3}\right)$, which are assigned to $\mathrm{Si}-\mathrm{O}-\mathrm{SiR}-(\mathrm{OMe})_{2}$ and $(\mathrm{Si}-\mathrm{O})_{2}-\mathrm{SiR}-\mathrm{OMe}$ units, indicating the formation of covalent bonds between silica and the organic moieties. ${ }^{25}$ The $\mathrm{R}$ group here corresponds to the

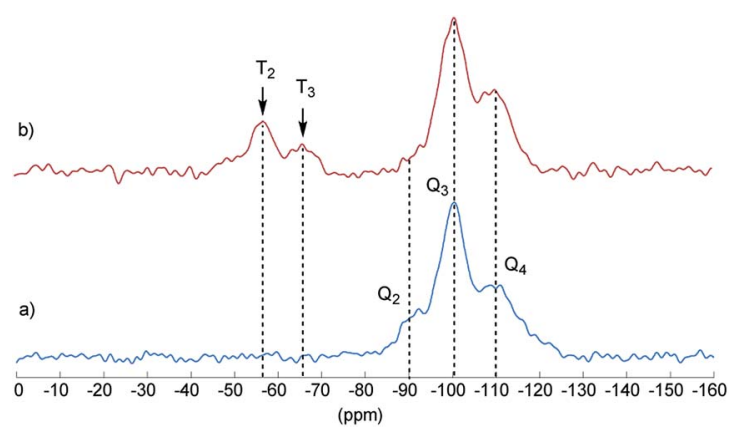

Fig. $2{ }^{1} \mathrm{H}-{ }^{29} \mathrm{Si} \mathrm{CP} /$ MAS NMR spectrum of unmodified silica $\mathrm{S}_{0}(\mathrm{a})$ and modified silica $S_{2}$ (b) with assignments of $T$ and $Q$ groups. $Q_{2}=$ geminal silanol, $Q_{3}=$ single silanol, $Q_{4}=$ siloxane bridges. Contact time $\tau=2 \mathrm{~ms}$. 


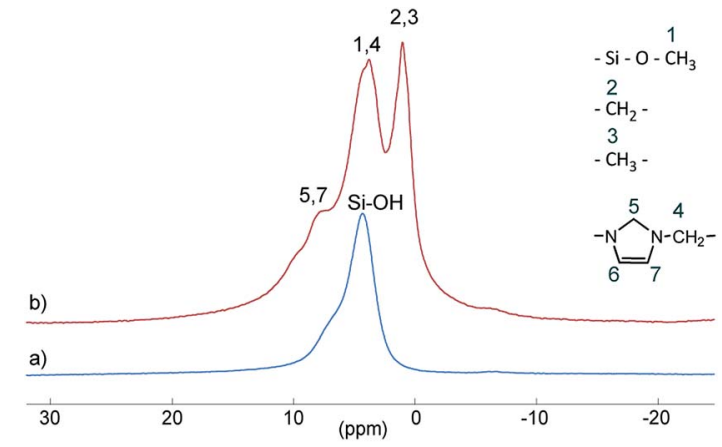

Fig. $3{ }^{1} \mathrm{H}$ MAS NMR spectra of unmodified silica $S_{0}(a)$ and modified silica $\mathrm{S}_{2}(\mathrm{~b})$.

alkylsilane moiety. The geminal silanol $\left(\mathrm{Q}_{2}\right)$ signal almost disappeared after modification of the silica surface with $\mathbf{A}_{\mathbf{2}}$, indicating that most of the $\mathrm{Q}_{2}$ sites have reacted and the majority of the residual silanol groups are of $\mathrm{Q}_{3}$ type. Additionally, the grafted alkylsilane on the surface of $\mathbf{S}_{2}$ can be detected by ${ }^{1} \mathrm{H}$ MAS NMR spectroscopy (see Fig. 3). The spectrum of the pristine silica $\mathbf{S}_{\mathbf{0}}$ exhibits a broad signal at about $4.4 \mathrm{ppm}$ which is assigned to $\mathrm{Si}-\mathrm{OH}$ groups. Additional signals in the spectrum of $\mathbf{S}_{2}$ are attributed to the imidazolium group (low field) and to the aliphatic groups of the alkyl chain (high field). The signals of unconverted alkoxysilane groups $\left(\mathrm{Si}-\mathrm{O}-\mathrm{CH}_{3}\right)$ and the signals of the $\mathrm{CH}_{2}$ groups attached to the imidazolium moiety $\left(\mathrm{N}^{-} \mathrm{CH}_{2}-\right)$ overlap with the $\mathrm{Si}-\mathrm{OH}$ signal.

In order to get information about the surface polarization of pristine and modified silica particles $\left(\mathbf{S}_{\mathbf{1 - 3}}\right)$, Zeta potential measurements were performed (see Fig. 4). The Zeta potential of pristine silica $\left(\mathbf{S}_{\mathbf{0}}\right)$ is essentially determined by the dissociation of the slightly acidic silanol groups on the particle surface $\left(\mathrm{Si}-\mathrm{OH} \leftrightarrow \mathrm{Si}-\mathrm{O}^{-}+\mathrm{H}^{+}\right)$. The resulting negatively charged surface causes the negative Zeta potential determined over the whole $\mathrm{pH}$ range from 2.5 to 10 . The isoelectric point (IEP) to be expected at lower $\mathrm{pH}$ values is outside the selected measuring range. The modification of $\mathbf{S}_{\mathbf{0}}$ with the alkoxysilanes $\mathbf{A}_{\mathbf{1}}$ and $\mathbf{A}_{\mathbf{3}}$ does not lead to significant changes in the shape of the Zeta potential curves. Obviously, the surface charge of $\mathbf{S}_{\mathbf{1}}$ and $\mathbf{S}_{\mathbf{3}}$ is

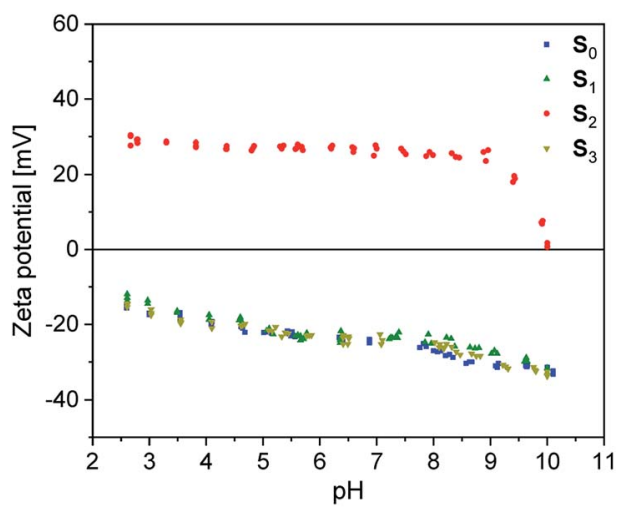

Fig. 4 Zeta potential of unmodified $\left(\mathrm{S}_{0}\right)$ and alkoxysilane modified silica fillers $\left(\mathrm{S}_{1-3}\right)$ in dependence of $\mathrm{pH}$. not strongly influenced by the modification. Here, it is assumed that the Zeta potential is mainly determined by remaining unreacted silanol groups whereas the influence of the grafted non-dissociable alkylsilane groups is negligible.

Completely different behavior is seen in $\mathbf{S}_{\mathbf{2}}$, which was modified with $\mathbf{A}_{\mathbf{2}}$. The cationic alkyl imidazolium groups at the surface of $\mathbf{S}_{2}$ result in a basic surface with a positive Zeta potential. Neutralization of the surface charge only occurs at the IEP at $\mathrm{pH}=10$. Evidently, the influence of the imidazolium groups distinctly overcompensates the influence of unreacted silanol groups.

\section{Rubber-silica composites}

Composites $\mathbf{C}_{\mathbf{0}-3}$ were prepared by mixing pristine silica $\left(\mathbf{S}_{\mathbf{0}}\right)$ or pre-silanized particles $\left(\mathbf{S}_{\mathbf{1}_{-3}}\right)$ respectively with a master batch of BIIR and unreacted 1-butylimidazole (1) in an internal mixer at $40{ }^{\circ} \mathrm{C}$ (ex situ silanization approach). This procedure proved to be advantageous, since direct mixing of the silica particles with BIIR-i was difficult because of the higher viscosity of BIIR-i compared to unmodified BIIR.

For comparison, the silanization of the silica particles was also performed during compounding (in situ silanization approach, $\mathbf{C}_{\mathbf{4 - 5}}$ ). For this, the master batch was consecutively mixed at $110{ }^{\circ} \mathrm{C}$ with pristine silica $\mathbf{S}_{\mathbf{0}}$ and the alkoxysilanes $\mathbf{A}_{\mathbf{1}}$ and $\mathbf{A}_{3}$ respectively. Due to the high shear forces, the temperature rose to $c a .140{ }^{\circ} \mathrm{C}$, which is nearly the optimal temperature for the in situ silanization reaction. It is assumed that the reaction with $\mathbf{A}_{\mathbf{1}}$ leads directly to the formation of $\mathbf{S}_{\mathbf{1}}\left(\mathbf{C}_{\mathbf{4}}\right)$, while in the reaction with $\mathbf{A}_{\mathbf{3}}$ initially forms $\mathbf{S}_{\mathbf{3}}$ which subsequently converts to $\mathbf{S}_{2}$ by reaction of the bromine group with $\mathbf{1}\left(\mathbf{C}_{5}\right)$.

Finally, all mixtures $\left(\mathbf{C}_{\mathbf{0}-5}\right)$ were homogenized in a two-roll mixing mill and then molded at $120^{\circ} \mathrm{C}$ for 30 minutes. Based on our previous results, ${ }^{19,20}$ it is assumed that during this procedure BIIR-i is formed quantitatively by conversion of the polymer bound bromine groups with $\mathbf{1}$ according to Scheme 1 . This reaction starts at temperatures above $50^{\circ} \mathrm{C}$ and is assumed to be completed during molding. After molding, test bars of the composites were punched out and used for mechanical and selfhealing tests.

Owing to the specific kinds of functional groups on the surface of $\mathbf{S}_{\mathbf{0 - 2}}$ (silanol, alkyl, imidazolium), composites $\mathbf{C}_{\mathbf{0 - 2}}$ presumably do not undergo changes in their filler surface functionality during compounding. Therefore, clearer correlations of their structure-property relationships are expected. In contrast, chemical reactions should occur on the filler surface during the preparation of $\mathbf{C}_{3-5}$, as is intended. For these samples, the results have to be regarded critically, since the extent of reactions at the particle surface cannot be accurately determined. Because of their presumably more defined structure, the focus of the following discussion is mainly placed on samples $\mathbf{C}_{\mathbf{0 - 2}}$. Results concerning the reactive systems $\mathbf{C}_{3-5}$ are documented in the ESI (SI3-SI7 $\dagger$ ) and discussed comparatively at the end.

Structurally, three different kinds of composites were obtained, distinguished by the functional groups present on the surface of their fillers (see Table 1). In the following (Fig. 5-8) 
and in the ESI (SI3-SI7 $\dagger$ ), the color of the curves indicates the specific functional groups. Blue stands for silanol groups $\left(\mathbf{C}_{\mathbf{0}}\right)$, green for alkyl groups $\left(\mathbf{C}_{\mathbf{1}}, \mathbf{C}_{\mathbf{4}}\right)$, red for ionic imidazolium groups $\left(\mathbf{C}_{2-3}, \mathbf{C}_{5}\right)$ and black for BIIR-i.

\section{Dynamic mechanical analysis}

The DMA temperature sweeps of $\mathbf{C}_{\mathbf{0 - 2}}$ and pure BIIR-i are depicted in Fig. 5. The storage modulus curves in Fig. 5a show a strong filler influence on the dynamic behavior of the composites. Compared to BIIR-i, the composites exhibit distinctly increased storage moduli in the application relevant temperature range. This effect is most pronounced in the composite with pristine silica $\left(\mathbf{C}_{\mathbf{0}}\right)$. For composites with
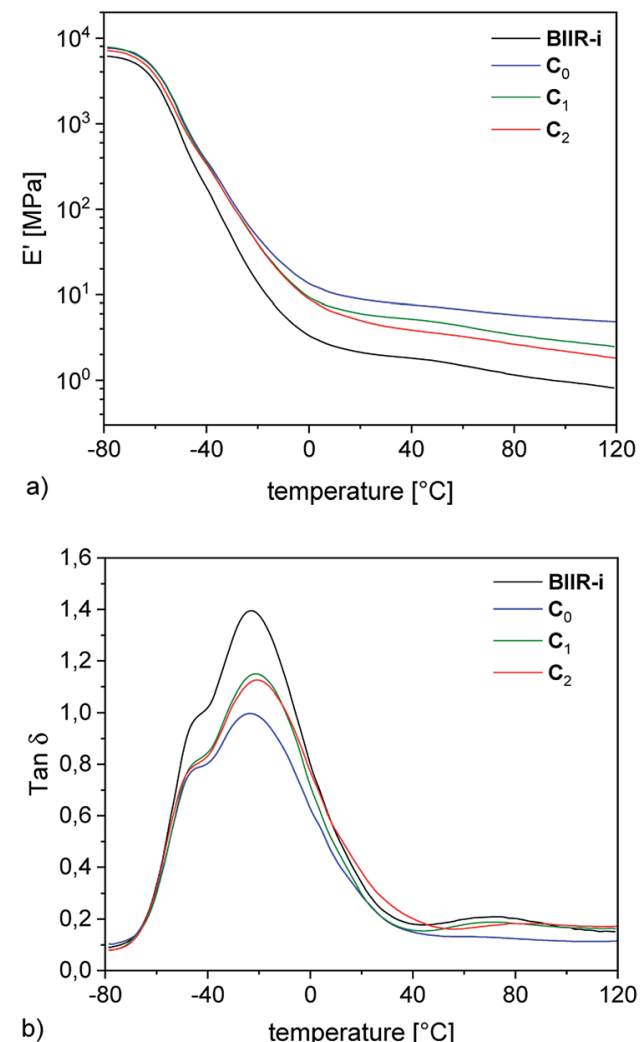

b)

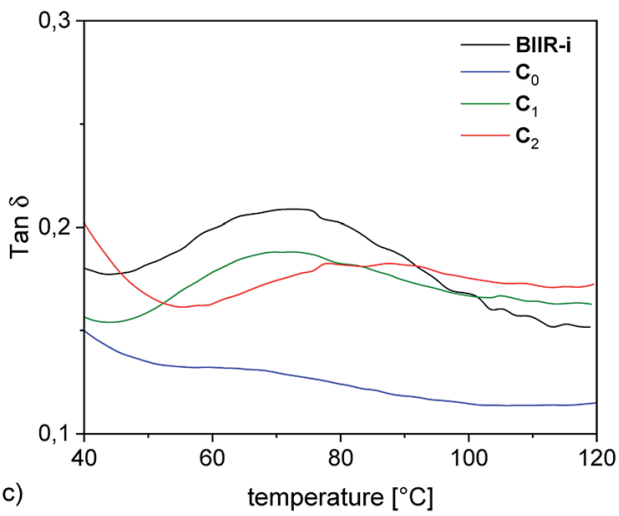

Fig. 5 DMA temperature sweep measurements of rubber-silica composites $\mathrm{C}_{0-2}$ and BIIR-i (a) storage modulus plots (b) $\tan \delta$ plots (c) enlarged section of the $\tan \delta$ plots.

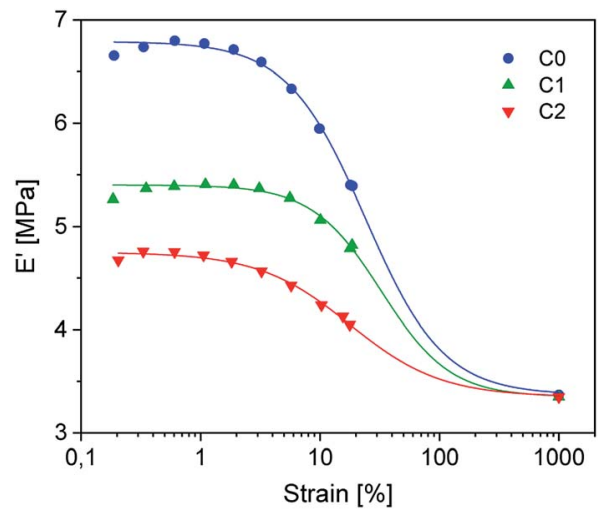

Fig. 6 DMA temperature strain sweep measurements of rubber-silica composites $\mathrm{C}_{0-2}$. The symbols represent the measured variables. The lines are fitted according to the Kraus model.

modified silica $\left(\mathbf{C}_{\mathbf{1 - 2}}\right)$, the reinforcing effect is somewhat weaker, with slightly better values for the sample with alkyl functional groups on the filler surface $\left(\mathbf{C}_{\mathbf{1}}\right)$.

Regarding the reinforcing effect, the $\tan \delta$ curves shown in Fig. 5b reveal a similar tendency. Generally, all samples exhibit the typical broad relaxation at the glass transition of BIIR with the maximum at about $-22{ }^{\circ} \mathrm{C}$. This relaxation is particularly pronounced for BIIR-i and decreases strongly in $\mathbf{C}_{\mathbf{0}}$. The samples with modified silica $\left(\mathbf{C}_{\mathbf{1 - 2}}\right)$ are somewhere in between. Both the storage moduli and the low temperature relaxation are indicators of the prevailing network density in the composites, which is relatively small in BIIR-i and becomes more pronounced upon compounding with silica.

The dynamic behavior of the composites correlates well with the surface properties of the filler regardless of whether silanization was performed in situ or ex situ. Zeta potential measurements revealed an acidic surface of pristine silica which obviously causes increased interactions with the basic imidazolium groups of BIIR-i in $\mathbf{C}_{\mathbf{0}}$ resulting in reduced chain mobility within the composite network. Introduction of flexible alkyl groups $\left(\mathbf{C}_{\mathbf{1}}\right)$ does not significantly influence the surface polarity of the fillers, but leads to shielding effects which reduce interactions between the filler and the matrix slightly. In the composite with the imidazolium modified filler $\left(\mathbf{C}_{2}\right)$, ionic interactions between the components are assumed which, however, do not exceed the effect of acid-base interactions in $\mathrm{C}_{\mathbf{0}}$.

In the $\tan \delta$ curves, a further small relaxation at temperatures above $40{ }^{\circ} \mathrm{C}$ is visible (see Fig. 5c), which is attributed to reversible network formation processes in BIIR-i. ${ }^{20}$ Again, this relaxation is only weakly pronounced in $\mathbf{C}_{\mathbf{0}}$ due to the acid-base interactions between the rubber matrix and the filler. In comparison to BIIR-i, this relaxation is slightly reduced in $\mathbf{C}_{\mathbf{1}}$ due to the shielding effect of the aliphatic groups. In $\mathbf{C}_{2}$, this relaxation is shifted to higher temperatures. For this sample, the formation of larger ionic associates is assumed, whose complete dissolution requires higher temperatures.

For the samples with undefined filler surface functionalization $\left(\mathbf{C}_{3-5}\right.$, see ESI SI3c $\left.\dagger\right)$ the relaxation behavior in this temperature range is not completely clear. However, this 

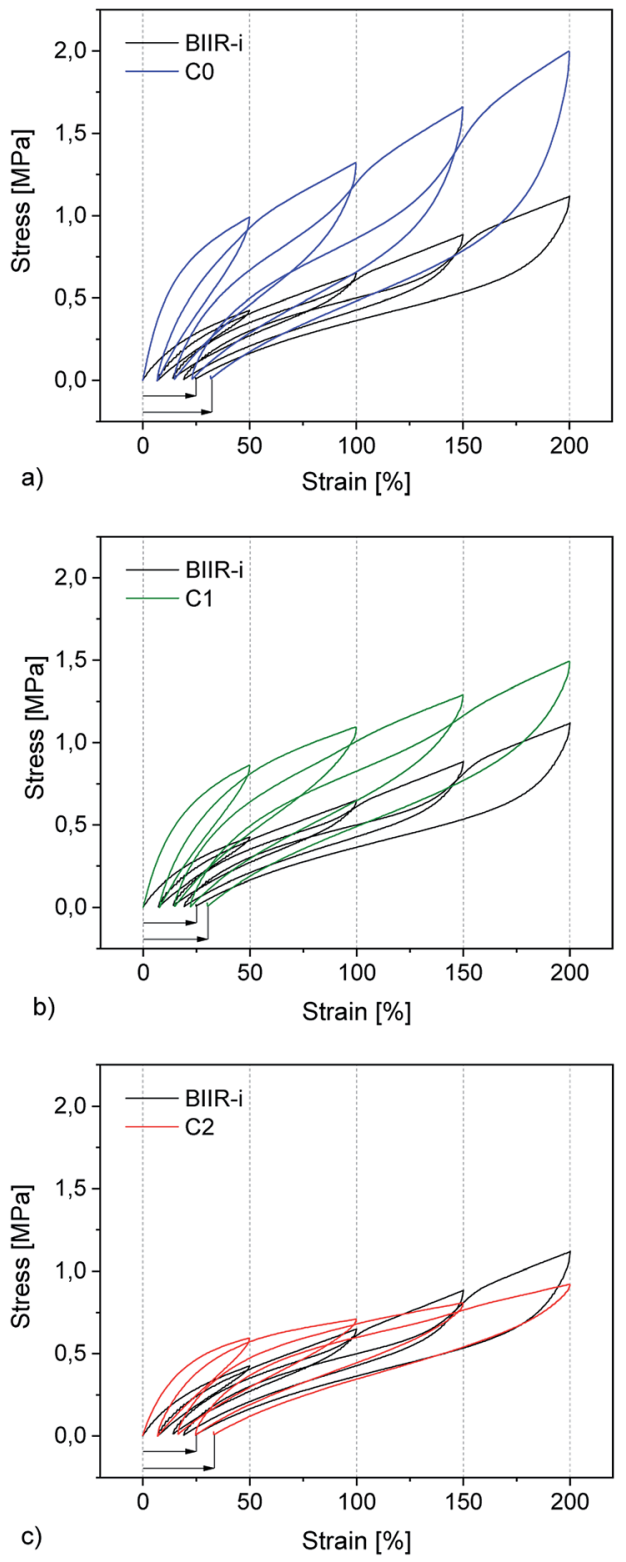

Fig. 7 Mechanical hysteresis curves of (a) $C_{0}$, (b) $C_{1}$, and (c) $C_{0}$ in comparison to BIIR-i.

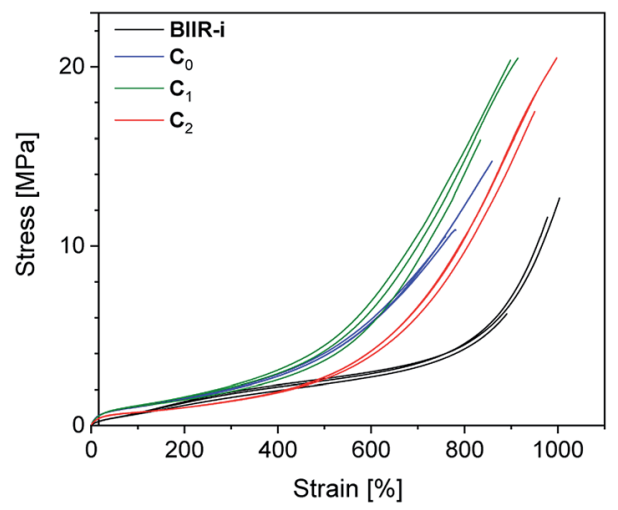

Fig. 8 Stress-strain curves of composites $\mathrm{C}_{0-2}$ compared to BIIR-i. relaxation tends to appear at lower temperature for composites with aliphatic substituents on the filler surface. This is an additional indication of the assumed shielding effect of aliphatic substituents.

An essential structural influence on the properties of composites lies in the distribution of the fillers. Competing interactions of the filler particles with each other or with the matrix lead to the formation of particle clusters or filler-filler networks which are susceptible to external mechanical forces.

Stress induced re-agglomeration processes usually referred to as "filler flocculation" can be investigated by dynamic mechanical amplitude sweep measurements. Such investigations give hints about the stability of these filler-filler networks and their influence on the mechanical performance of composite materials. Changes in the storage and loss modulus with increasing strain, well known as the Payne effect, ${ }^{28}$ can be attributed to a break-down of the filler network and to an increased energy dissipation during dynamic mechanical load.

Dynamic mechanical strain sweep measurements of $\mathbf{C}_{\mathbf{0 - 2}}$ are shown in Fig. 6 (for $\mathbf{C}_{3-5}$ see ESI SI $4 \dagger$ ).

The data fit (solid lines) was performed according to the Kraus model (eqn (4)) ${ }^{29}$ under consideration of the hydrodynamic reinforcement values ( $E_{\min }^{\prime}$ at $1000 \%$ strain) extrapolated using the Chen and Acrivos approach (eqn (3)) $)^{30,31}$ where the value $b$ is assumed to be 5.01 .

$$
\begin{gathered}
E_{\mathrm{c}}=E_{\mathrm{m}}\left(1+2.5 \varphi+b \varphi^{2}\right) \\
E^{\prime}(\gamma)=E_{\text {min }}^{\prime}+\left(\left(E_{\text {max }}^{\prime}-E_{\min }^{\prime}\right) /\left(1+\left(\frac{\gamma}{\gamma_{\mathrm{c}}}\right)^{2 \mathrm{~m}}\right)\right)
\end{gathered}
$$

$E_{\mathrm{c}}$ and $E_{\mathrm{m}}$ are the dynamic elastic moduli of the composite and the pure matrix obtained from dynamic strain sweep measurements, $\varphi$ is the volume fraction of silica (30 phr in the present study), $E^{\prime}(\gamma)$ is the storage modulus at a given dynamic strain, $E_{\max }^{\prime}$ is the storage modulus at very low dynamic strain, $E_{\text {min }}^{\prime}$ represents a strain regime at which only hydrodynamic reinforcement effects exist ${ }^{32}$ and interactions between the particles become negligible, $\gamma$ is the tensile strain amplitude, $\gamma_{c}$ is the critical strain amplitude defining the point where $E^{\prime}(\gamma)-E_{\min }^{\prime}$ becomes $50 \%$ of $E_{\max }^{\prime}-E_{\min }^{\prime}, m$ is a constant which is related to the specific fractal dimension of the filler clusters determining the shape of the curve. ${ }^{33}$

The extrapolation of $E_{\min }^{\prime}$ using eqn (3) was necessary since measurements at high dynamic strain amplitudes are experimentally limited. ${ }^{34}$ The difference $E_{\max }^{\prime}-E_{\min }^{\prime}$ can be regarded as a characteristic measure for the strength of the filler-filler network. The characteristic values of the Kraus model determined are summarized in Table 3.

Regarding the $E_{\max }^{\prime}$ values of $\mathbf{C}_{\mathbf{0 - 2}}$, the trend is the same as found in the temperature sweep measurements. $E_{\max }^{\prime}$ decreases in the order $\mathbf{C}_{\mathbf{0}}>\mathbf{C}_{\mathbf{1}}>\mathbf{C}_{\mathbf{2}}$. A slightly different tendency is seen for $\gamma_{c}$, the point at which $50 \%$ of the filler-filler contacts are broken. ${ }^{35}$ Here, the order is $\mathbf{C}_{\mathbf{1}}>\mathbf{C}_{\mathbf{0}}>\mathbf{C}_{\mathbf{2}}$. Actually, the stronger the filler network of the flocculated filler particles, the higher the Payne effect $\left(E_{\max }^{\prime}-E_{\min }^{\prime}\right)$. In the case of $\mathbf{C}_{\mathbf{0}}$, the flocculation 
Table 3 Fit parameters of the Kraus model for composites $\mathrm{C}_{0-5}$

\begin{tabular}{|c|c|c|c|c|c|}
\hline Sample & $\begin{array}{l}\text { Silica surface functional } \\
\text { groups }\end{array}$ & $E_{\max }^{\prime}[\mathrm{MPa}]$ & $E_{\min }^{\prime}[\mathrm{MPa}]$ & $\gamma_{\mathrm{c}}$ & $2 m$ \\
\hline $\mathbf{C}_{\mathbf{0}}^{a}$ & Silanol & 6.79 & 3.37 & $24.00 \pm 1.04$ & $1.33 \pm 0.08$ \\
\hline $\mathbf{C}_{2}^{a, b}$ & Imidazolium & 4.75 & 3.35 & $17.77 \pm 1.13$ & $1.13 \pm 0.08$ \\
\hline $\mathbf{C}_{3}^{b, c}$ & Imidazolium & 3.99 & 3.34 & $5.42 \pm 1.73$ & $1.73 \pm 0.22$ \\
\hline $\mathbf{C}_{4}{ }_{4}^{c, d}$ & Alkyl & 5.75 & 3.35 & $20.80 \pm 1.54$ & $1.48 \pm 0.18$ \\
\hline
\end{tabular}

${ }^{a}$ No change in surface functionality during compounding. ${ }^{b}$ Ex situ particle silanization approach. ${ }^{c}$ Change in surface functionality during compounding. ${ }^{d}$ In situ particle silanization approach.

tendency of the unmodified silica particles is strong, which leads to the most pronounced Payne effect. A modification of the filler surface by alkyl grafts $\left(\mathbf{C}_{\mathbf{1}}\right)$ reduces the difference in surface energies between filler and polymer matrix and leads to a reduced Payne effect as expected. In the case of $\mathbf{C}_{2}$, it is assumed that strong ionic interactions between the filler and the matrix prevent the formation of a strong filler network resulting in a lower critical strain. A very low value of $\gamma_{c}$ is found in the case of $\mathbf{C}_{3}$, indicating that the filler flocculation in this sample is strongly suppressed. Here, the reaction of the bromine groups on the filler surface with imidazole takes place during molding. Because of the static molding conditions, the resulting ionic groups do not assist the dispersion. However, if the ionic groups are formed during mixing as in $\mathbf{C}_{2}$, the ionic interactions between silica and the rubber chains facilitate the dispersion of the silica.

\section{Tensile properties}

Cyclic tensile tests and stress-strain measurements were performed on composites $\mathbf{C}_{\mathbf{0 - 5}}$ and compared to BIIR-i. The mechanical hysteresis curves and stress-strain curves of BIIR-i and the rubber composites $\mathbf{C}_{\mathbf{0 - 2}}$ are shown in Fig. 7 and 8 (for $\mathbf{C}_{3-5}$, see ESI SI5 and SI6†).

As can be seen from Fig. 7, all samples exhibit distinct strain softening (Mullin's effect) which can be attributed to irreversible rearrangements in the network. Due to the lack of a classical covalent network, permanent deformation occurs with increasing stress, resulting in increasing residual strain values after each cycle. The arrow lengths in Fig. 7 indicate the residual strain after four cycles. For the composites, these values are somewhat higher as for BIIR-i, showing that the incorporation of fillers results in higher levels of irreversible rearrangements during strain. On the other hand, the incorporation of fillers causes a significant reinforcing effect which can be seen in a steeper curve progression at low strain (up to 200\%). This effect is strongest in the case of $\mathbf{C}_{\mathbf{0}}$ and relatively weak for $\mathbf{C}_{2}$. This is in very good correlation with the DMA results and confirms our assumptions concerning the influence of the different filler surfaces. The enclosed area in the hysteresis loops is a measure of the energy dissipated in the material. The obtained results are in good agreement with the findings of the Payne effect measurements shown above. The reinforcing effect of the fillers clearly appears also at higher elongation (see
Fig. 8). The stress-strain curves, measured three times for each sample, show a reasonably reproducible curve progression. All samples show pronounced strain hardening which, however, starts earlier in the composites compared to BIIR-i. Additionally, these measurements confirm the similarity of the mechanical behavior of $\mathbf{C}_{2}$ to that of unreinforced BIIR-i. Concerning the tensile strengths and elongation at break values (see Table 4), the influence of the filler type is not completely clear. We assume that the different filler types lead to different degrees of homogeneity of the filler distribution, which sensitively influence the ultimate rubber properties. Although this effect is important for technical rubber applications, it is not an issue for our fundamental study here. We have shown that an improvement of the tensile strengths by adding fillers tends to occur in all cases. Taking into account that no covalent crosslinking occurs, the mechanical behavior of all samples must be considered excellent. This applies especially for the samples $\mathbf{C}_{\mathbf{1}}$ and $\mathbf{C}_{2}$, the filler surface of which was modified with aliphatic and ionic functional groups respectively.

\section{Self-healing behavior}

To determine how compounding with silica affects the excellent self-healing behavior of ionically modified BIIR, self-healing tests were performed for $\mathbf{C}_{\mathbf{0}-\mathbf{3}}$ and compared to BIIR-i. For this, test bars of the samples were cut in the middle and then allowed to mend for $16 \mathrm{~h}$ at $70{ }^{\circ} \mathrm{C}$ under slight pressure. The mended samples were subjected to tensile tests. As an example,

Table 4 Tensile properties and healing efficiencies of composites $\mathrm{C}_{0-}$ 5 and BIIR-i

\begin{tabular}{lrrll}
\hline Sample & $\sigma_{\mathrm{b}(\mathrm{v})}{ }^{a}[\mathrm{MPa}]$ & \multicolumn{1}{c}{$\varepsilon_{\mathrm{b}(\mathrm{v})}{ }^{b}[\%]$} & $H_{\sigma}{ }^{c}[\%]$ & $H_{\varepsilon}{ }^{d}[\%]$ \\
\hline BIIR-i & $10.2 \pm 3.5$ & $960 \pm 60$ & $87 \pm 50$ & $100 \pm 11$ \\
$\mathbf{C}_{\mathbf{0}}$ & $12.0 \pm 2.3$ & $800 \pm 50$ & $40 \pm 25$ & $55 \pm 19$ \\
$\mathbf{C}_{\mathbf{1}}$ & $18.9 \pm 2.6$ & $880 \pm 40$ & $43 \pm 23$ & $71 \pm 12$ \\
$\mathbf{C}_{\mathbf{2}}$ & $18.9 \pm 1.5$ & $970 \pm 30$ & $32 \pm 16$ & $72 \pm 12$ \\
$\mathbf{C}_{3}$ & $10.1 \pm 0.7$ & $1030 \pm 30$ & $13 \pm 8$ & $41 \pm 27$ \\
$\mathbf{C}_{\mathbf{4}}$ & $11.7 \pm 1.5$ & $820 \pm 30$ & n.d. ${ }^{e}$ & n.d. \\
$\mathbf{C}_{5}$ & $9.4 \pm 0.5$ & $790 \pm 20$ & n.d. & n.d.
\end{tabular}

${ }^{a}$ Average tensile stress at break of the virgin samples. ${ }^{b}$ Average elongation at break of the virgin samples. ${ }^{c}$ Healing efficiency related to the tensile stress at break. ${ }^{d}$ Healing efficiency related to the elongation at break. ${ }^{e}$ Not determined. 


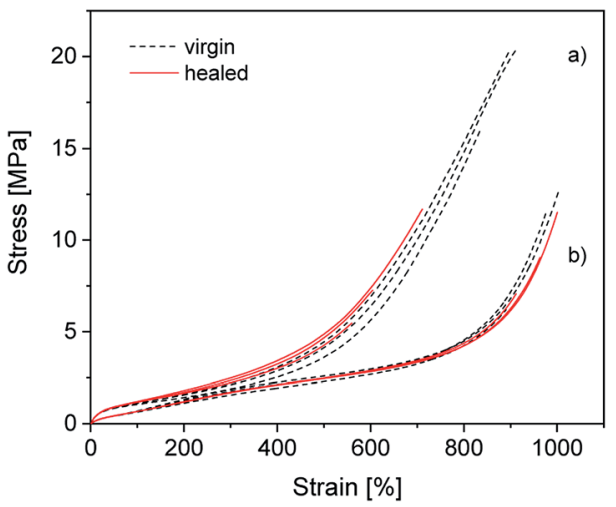

Fig. 9 Stress-strain curves of (a) $C_{1}$ and (b) BIIR-i. The black (dotted) and the red (solid) curves represent the virgin and the healed samples respectively.

the self-healing effect is demonstrated for $\mathbf{C}_{\mathbf{1}}$ and BIIR-i by means of stress-strain curves before and after healing (see Fig. 9). Respective plots for the other samples are shown in Fig. SI7 in the ESI. $\dagger$ Tensile stress and elongation at break related healing efficiencies $H_{\sigma}$ and $H_{\varepsilon}$ for all samples (mean values of three measurements) are summarized in Table 4 . The results confirm the pronounced self-healing behavior of BIIR-i at reasonable overall performance, as already discussed earlier. $^{19,20}$ The healing efficiencies of the composites are distinctly lower than for BIIR-i but still at a reasonable level. For the composites with surface-modified particles $\left(\mathbf{C}_{\mathbf{1 - 2}}\right)$ in particular, the stress at break values after healing $\left(\sigma_{\mathrm{b}(\mathrm{h})}=8.1\right.$, 6.0 MPa) are comparable to those of pristine BIIR-i $\left(\sigma_{\mathrm{b}(\mathrm{v})}=10.2\right.$ $\mathrm{MPa})$.

For the composites, the same self-healing mechanism as previously discussed for BIIR-i is assumed. ${ }^{19,20}$ The ionic imidazolium groups of the rubber form a dynamic network which can be healed in case of damage by rearranging ionic clusters. The self-healing process is furthered by the rubber's chain mobility. The silica particles in the composites are assumed to be integrated into the dynamic network via interactions of their functional groups with the imidazolium groups. This is reflected in the distinct reinforcing effect discussed above. On the other hand, the particle-matrix interactions seem to suppress the self-healing tendency. This can easily be explained (qualitatively) by a recently suggested modified slip-link model of entangled chains with reversible cross-links in the molten state, which in general favor the self-healing effect. ${ }^{38}$ The presence of additional, slowly moving particles anchored to the polymer will further restrict the mobility of the polymers, resulting in a significant extension of the characteristic self-healing time and thus in a reduced self-healing character.

\section{Reactive compounding}

Comparative studies were made on composites with in situ modification of the particle surfaces $\left(\mathbf{C}_{3-5}\right)$. Results concerning dynamic mechanical behavior, tensile properties, and selfhealing behavior of these composites in comparison with $\mathbf{C}_{\mathbf{0}-\mathbf{2}}$ are documented in the ESI (SI3-SI7†). The advantage of the in situ modification is the saving of a separate processing step (filler functionalization). But it remains unclear to what extent the surface functionalization takes place in this approach. Deviations in the mechanical performance of $\mathbf{C}_{3-5}$ in comparison to $\mathbf{C}_{\mathbf{1 - 2}}$ indicate that such differences exist. A more detailed exploration of these differences might be the subject of a separate study.

Generally, the tensile properties of $\mathbf{C}_{3-5}$ are lower than those of $\mathbf{C}_{\mathbf{1 - 2}}$ (see Table 4). Nevertheless, with stress at break values from 9.4 to $11.7 \mathrm{MPa}$ and elongation at break values from 790 to $1030 \%$, the mechanical properties are satisfactory and comparable with those of BIIR-i. In addition, compounds $\mathbf{C}_{\mathbf{4}-5}$ show a clear reinforcing effect, which manifests in the earlier onset of strain hardening (see ESI SI6†). Although the relaxation behavior and tensile properties of $\mathbf{C}_{3-5}$ do not fully match those of $\mathbf{C}_{\mathbf{1 - 2}}$ (see ESI SI3-SI6†), the influence of the functional groups on the filler surface as discussed for $\mathbf{C}_{\mathbf{1 - 2}}$ is confirmed. Both DMA (see ESI SI3 and SI $4 \dagger$ ) and tensile tests (see ESI SI5 and SI6†) show the same tendency. Concerning the influence of the filler surface functionality on the reinforcing effect, the following order could be observed: silanol $\left(\mathbf{C}_{\mathbf{0}}\right)>$ aliphatic $\left(\mathbf{C}_{\mathbf{1}, \mathbf{4}}\right)>$ imidazolium $\left(\mathbf{C}_{2,3,5}\right)$. There is a noticeable deviation in the behavior of $\mathbf{C}_{3}$ (see ESI SI4 and SI6 $\dagger$ ), which underlines the uncertainties of reactive compounding.

\section{Conclusions}

The main purpose of the present work was to further improve the inherently very good characteristics of ionically modified bromobutyl rubber (BIIR-i) by compounding with surfacemodified silica without sacrificing its excellent self-healing behavior. The compounding was carried out in a reactive process in which the ionic modification of BIIR occurred simultaneously by conversion of the bromine groups with 1butylimidazole. The interactions between the rubber matrix and silica were adjusted by functional groups on the filler surface. In addition to the naturally occurring silanol groups of silica, alkyl and imidazolium groups were introduced via silanization of the particle surface.

The overall performance of silica filled BIIR-i has proven very promising. With tensile strengths of up to $19 \mathrm{MPa}$ and elongation at break values of roughly $1000 \%$, maximum values for a non-covalently cross-linked rubber composite are achieved. These values are significantly better than those of sulfurcrosslinked composites of BIIR with carbon black and layered silicates in which no self-healing occured. ${ }^{36,37}$ The healing efficiencies of the composites $\left(H_{\sigma}=32-40 \%, H_{\varepsilon}=55-72 \%\right)$ are reduced in comparison to BIIR-i $\left(H_{\sigma}=87 \%, H_{\varepsilon}=100 \%\right)$, but the absolute tensile stress and elongation at break values of the composites after healing are comparable with those of BIIR-i.

The reinforcing effect caused by the filler could be proven by DMA and stress-strain measurements. In the tensile tests of the composites, an earlier onset of strain hardening and a higher stress-build up at low strain is observed. In the DMA measurements, the reinforcing effect is reflected in an increased storage modulus. The $\tan \delta$ curves of the composites show less 
pronounced glass transitions indicating reduced chain mobility.

All measurements point to a distinct influence of the filler surface functionalization. Regarding the type of functional groups, the reinforcing effect decreases in the following order: silanol $>$ alkyl $>$ imidazolium. The particularly strong reinforcing effect of pristine silica $\left(\mathbf{S}_{\mathbf{0}}\right)$ is attributed to the slightly acidic nature of its silanol groups which undergo strong interactions with the basic imidazolium groups of BIIR-i. For the composites with imidazolium modified particles $\left(\mathbf{C}_{2-3,5}\right)$, a relatively small reinforcing effect was found. Their behavior resembles that of BIIR-i. This is attributed to the similarity of the interacting groups. Both the filler and the matrix of these composites possess imidazolium groups which are assumed to aggregate into ionic clusters which obviously respond similarly to tensile loading as the clusters in BIIR-i. Notably, sample $\mathbf{C}_{2}$ shows a significantly better tensile strength than BIIR-i. In the case of composites with alkyl modified particles $\left(\mathbf{C}_{\mathbf{1}, \mathbf{4}}\right)$, the reinforcing effect is caused by the prevalence of dispersion forces between the nonpolar parts of the rubber backbone and the filler surface which can be pronounced at high surface loading.

The mechanical performance of the composites with in situ particle modification $\left(\mathbf{C}_{3-5}\right)$ remains behind that of the composites with pre-modified particle surfaces $\left(\mathbf{C}_{\mathbf{0 - 2}}\right)$. This is attributed to uncomplete conversions on the filler surface. Nevertheless, some improvements in comparison to BIIR-i give rise to the assumption that further improvements might be possible for composites with in situ modified particles. This will be the subject of further investigations.

\section{Conflicts of interest}

There are no conflicts to declare.

\section{Acknowledgements}

This work was supported by the Deutsche Forschungsgemeinschaft (DFG, BO 1121/7-1, BO 1121/9-1, HE 4466/32-1) in the Priority Program (Schwerpunktprogramm, SPP 1568) "Design and Generic Principles of Self-Healing Materials". The authors thank Holger Scheibner for mechanical tests, Liane Häußler and Kerstin Arnold for TGA measurements, Dr Petr Formanek for TEM measurements and René Jurk for technical support.

\section{References}

1 P. Cordier, F. Tournilhac, C. Soulie-Ziakovic and L. Leibler, Nature, 2008, 451, 977-980.

2 C. H. Xu, L. M. Cao, B. F. Lin, X. Q. Liang and Y. K. Chen, ACS Appl. Mater. Interfaces, 2016, 8, 17728-17737.

3 M. Hernandez, A. M. Grande, W. Dierkes, J. Bijleveld, S. van der Zwaag and S. J. Garcia, ACS Sustainable Chem. Eng., 2016, 4, 5776-5784.

4 X. Kuang, G. M. Liu, X. Dong and D. J. Wang, Macromol. Mater. Eng., 2016, 301, 535-541.
5 H. P. Xiang, M. Z. Rong and M. Q. Zhang, ACS Sustainable Chem. Eng., 2016, 4, 2715-2724.

6 D. Wang, J. Guo, H. Zhang, B. C. Cheng, H. Shen, N. Zhao and J. Xu, J. Mater. Chem. A, 2015, 3, 12864-12872.

7 A. C. Schüssele, F. Nübling, Y. Thomann, O. Carstensen, G. Bauer, T. Speck and R. Mülhaupt, Macromol. Mater. Eng., 2012, 297, 411-419.

8 C. H. Xu, X. H. Huang, C. H. Li, Y. K. Chen, B. F. Lin and X. Q. Liang, ACS Sustainable Chem. Eng., 2016, 4, 6981-6990.

9 X. Y. Jia, J. F. Mei, J. C. Lai, C. H. Li and X. Z. You, Macromol. Rapid Commun., 2016, 37, 952-956.

10 Y. You, W. Y. Huang, A. Q. Zhang and Y. L. Lin, J. Polym. Sci., Part A: Polym. Chem., 2016, 54, 3760-3768.

11 T. F. Wu and B. Q. Chen, RSC Adv., 2017, 7, 20422-20429.

12 X. H. Liu, C. H. Lu, X. D. Wu and X. X. Zhang, J. Mater. Chem. A, 2017, 5, 9824-9832.

13 T. F. Wu and B. Q. Chen, ACS Appl. Mater. Interfaces, 2016, 8, 24071-24078.

14 Y. H. Zhan, Y. Y. Meng and Y. C. Li, Mater. Lett., 2017, 192, 115-118.

15 S. W. Wu, J. H. Li, G. P. Zhang, Y. M. Yao, G. Li, R. Sun and C. P. Wong, ACS Appl. Mater. Interfaces, 2017, 9, 3040-3049.

16 J. Norambuena-Contreras, V. G. Aguilar and I. GonzalezTorre, Constr. Build. Mater., 2015, 94, 45-56.

17 J. S. Parent, S. M. Malmberg and R. A. Whitney, Green Chem., 2011, 13, 2818-2824.

18 J. S. Parent, A. M. J. Porter, M. R. Kleczek and R. A. Whitney, Polymer, 2011, 52, 5410-5418.

19 A. Das, A. Sallat, F. Böhme, M. Suckow, D. Basu, S. Wießner, K. W. Stöckelhuber, B. Voit and G. Heinrich, ACS Appl. Mater. Interfaces, 2015, 7, 20623-20630.

20 M. Suckow, A. Mordvinkin, M. Roy, N. K. Singha, G. Heinrich, B. Voit, K. Saalwächter and F. Böhme, Macromolecules, 2018, 51, 468-479.

21 H. H. Le, F. Böhme, A. Sallat, S. Wießner, M. A. D. Landwehr, U. Reuter, K. W. Stöckelhuber, G. Heinrich, H. J. Radusch and A. Das, Macromol. Mater. Eng., 2017, 302, 1600385.

22 H. H. Le, S. Hait, A. Das, S. Wiessner, K. W. Stöckelhuber, F. Böhme, U. Reuter, K. Naskar, G. Heinrich and H. J. Radusch, eXPRESS Polym. Lett., 2017, 11, 230-242.

23 S. Mihara, R. N. Datta and J. W. M. Noordermeer, Rubber Chem. Technol., 2009, 82, 524-540.

24 D. Fischer, D. Pospiech, U. Scheler, R. Navarro, M. Messori and P. Fabbri, Macromol. Symp., 2008, 265, 134-143.

25 Q. Wang, G. A. Baker, S. N. Baker and L. A. Colon, Analyst, 2006, 131, 1000-1005.

26 V. Antochshuk and M. Jaroniec, Chem. Mater., 2000, 12, 2496-2501.

27 A. B. Scholten, J. W. de Haan, H. A. Claessens, L. J. M. van de Ven and C. A. Cramers, Langmuir, 1996, 12, 4741-4747.

28 A. R. Payne, in Reinforcement of elastomers, Interscience, New York, 1965, ch. 3, pp. 69-123.

29 G. Kraus, Rubber Chem. Technol., 1978, 51, 297-321.

30 H. S. Chen and A. Acrivos, Int. J. Solids Struct., 1978, 14, 349364.

$31 \mathrm{~J}$. Domurath, M. Saphiannikova and G. Heinrich, $K G K$, Kautsch. Gummi Kunstst., 2017, 70, 40-43. 
32 G. Heinrich, M. Klüppel and T. A. Vilgis, Curr. Opin. Solid State Mater. Sci., 2002, 6, 195-203.

33 G. Heinrich and T. A. Vilgis, Macromol. Symp., 1995, 93, 253260.

34 K. W. Stöckelhuber, A. S. Svistkov, A. G. Pelevin and G. Heinrich, Macromolecules, 2011, 44, 4366-4381.

35 S. R. Vaikuntam, E. S. Bhagavatheswaran, K. W. Stöckelhuber, S. Wießner, G. Heinrich and A. Das, Rubber Chem. Technol., 2017, 90, 467-486.
36 S. Praveen, P. K. Chattopadhyay, S. Jayendran, B. C. Chakraborty and S. Chattopadhyay, Polym. Compos., 2010, 31, 97-104.

37 A. H. Tsou and M. B. Measmer, Rubber Chem. Technol., 2006, 79, 281-306.

38 M. J. Mateyisi, J.-U. Sommer, K. K. Müller-Nedebock and G. Heinrich, J. Chem. Phys., 2018, 148, 244901. 